\title{
Consequence assessment of separator explosion for an oil production platform in South of Iran with PHAST Software
}

\author{
Abolfazl Naemnezhad ${ }^{1}$ Ali Akbar Isari ${ }^{1}$ Ebrahim Khayer $^{2}$. \\ Mojtaba Esfandiari Birak Olya ${ }^{1}$
}

Received: 6 January 2017 / Accepted: 9 February 2017 / Published online: 3 April 2017

(c) The Author(s) 2017. This article is an open access publication

\begin{abstract}
Non-stop growth in oil, gas and petrochemical industries and dramatic impact of corrosion due to reducing the useful life of equipment need to manage risk and analyze consequences of possible accidents make more clear. Corrosion can counted as the most threaten factor for reducing the life of equipment in oil, gas and petrochemical industries. Corrosion damages risk analyzing and consequences assessment of probable failure play remarkable role in corrosion management systems. Corrosion damage might cause to failure due to leakage. Initial visual inspections of the test separator ME-03 shows widely scattered local thin areas at the bottom of pressure vessel. This twophase separator (oil and gas) is one of the most critical equipment on old Nowrooz oil production platform in Bahregan district. The critical role of pressure vessel on oil production delayed inspection periods for more than 10 years and moreover this pressure vessel operate at $225 \mathrm{psi}, 100^{\circ} \mathrm{F}$ and the volume of $860 \mathrm{ft}^{3}$ liquid that consequence assessment of this object make more important. Consequence of probable explosion of pressure vessel due to corrosion progress analyzed through the commercial PHAST software. This paper look forward consequence assessment of explosion scenario with the PHAST software then provide a procedure for rerate of ME-03 for future safe servicing.
\end{abstract}

Keywords Fitness for service $\cdot$ Risk assessment $\cdot$ Local thin area $\cdot$ Pressure vessel $\cdot$ PHAST

Abolfazl Naemnezhad

A.Naemnezhad@yahoo.com

1 Petroleum University of Technology (PUT), Abadan, Islamic Republic of Iran

2 Iranian Offshore Oil Company (IOOC), Bahregan District, Islamic Republic of Iran

\section{Introduction}

In recent years there has been a significant increase in public awareness of the potential dangers posed by the usage of chemicals and their effects to both human beings and the environment (Soman and Sundararaj 2015).

Operational mistakes (such as elevated pressure and temperature beyond critical limits) in oil and gas industries that involve to chemical materials can cause catastrophic consequences to life and environment leading to financial loss. Major industrial hazards are generally associated with the potential for fire, explosion or dispersion of toxic chemicals (Brito and Almeida 2009; Dadashzadeh et al. 2013; Pitblado 2007; McIntyre et al. 2009; Bash and Casal 2007).

ME-03 test separator is one of the most critical equipment in old Nowrooz platform, sever servicing condition of ME-03 and necessity to continuing to service, make inspection periods postponed for more than 10 years. Detailed phased array ultrasonic testing (PAUT) shows widely scattered local thin areas in the bottom of ME-03.22 LTA found between 3 and 9 o' clock of cylindrical body and elliptical head. In some case, minimum measured thickness exceeds to $50 \%$ of original thickness and longitudinal extent of damage is more than $100 \mathrm{~cm}$. Water accumulation in the bottom of two-phase pressure vessel is the main factor of the corrosion. Fitness for service assessment of ME-03 clearly shows that pressure vessel can continue to service for 5 years. Long and high pressure servicing, critical role in production and location of pressure vessel are factors that make consequence analysis of probable explosion more important (Pandya et al. 2012; Nabhani and Esfandyari 2015).

PHAST (Process Hazard Analysis Software Tool) version 6.53.1 Software (DNV Corp.) was adopted in order to model the accident. PHAST examines the progress of a 

accidents in process plants (Bash and Casal 2007)
Table 1 Distribution of major

\begin{tabular}{ll}
\hline Type of accident & $\%$ \\
\hline Fire & 47 \\
Explosion & 40 \\
Gas cloud & 13 \\
\hline
\end{tabular}

Table 2 The most important type of accident and effects (Bash and Casal 2007)

\begin{tabular}{llll}
\hline Type of accident & $\begin{array}{l}\text { Probability } \\
\text { of occur- } \\
\text { rence }\end{array}$ & Potential for fatalities & $\begin{array}{l}\text { Potential for } \\
\text { economic } \\
\text { loss }\end{array}$ \\
\hline Fire & High & Low & $\begin{array}{l}\text { Intermediate } \\
\text { Explosion }\end{array}$ \\
Toxic release & Low & High & $\begin{array}{l}\text { High } \\
\text { low }\end{array}$ \\
\hline
\end{tabular}

chemical process incident from initial release through formation of a cloud or pool to final dispersion calculating concentration, fire radiation, toxicity and explosion overpressure. Due to its reliability and outstanding technical superiority, PHAST is utilized by over 300 organizations worldwide. PHAST is owned by Det Norske Veritas (DNV) and it is a comprehensive hazard analysis package, applicable to all stages of design and operation across a range of process and chemical industry sectors. It is used to identify situations which present potential hazards to life, property or the environment. Such scenarios might be removed by re-design of the process or plant, or modification of existing operational procedures. Scenarios which remain may be submitted for further analysis such as rigorous risk assessment, where necessary, using more sophisticated QRA tools such as SAFETI. The application can model many

Table 3 Damage estimates for common structures based on overpressure (Center for Chemical Process Safety 1999)

\begin{tabular}{|c|c|c|}
\hline \multicolumn{2}{|l|}{ Pressure } & \multirow[t]{2}{*}{ Damage } \\
\hline psig & $\mathrm{kPa}$ & \\
\hline 0.04 & 0.28 & Loud noise (143 dB), sonic boom, glass failure \\
\hline 0.1 & 0.69 & Breakage of small windows under strain \\
\hline 0.15 & 1.03 & Typical pressure for glass breakage \\
\hline 0.3 & 2.07 & $\begin{array}{l}\text { Unsafe distance" (probability } 0.95 \text { of no serious damage below chis value); projectile limit; some damage to house ceilings; } \\
10 \% \text { window glass broken }\end{array}$ \\
\hline 0.4 & 2.76 & Limited minor structural damage \\
\hline $0.5-1.0$ & 6.9 & Large and small windows usually shattered; occasional damage to window frames \\
\hline 0.7 & 4.8 & Minor damage to home structure \\
\hline 1.0 & 6.9 & Partial demolition of houses, made uninhabitable \\
\hline $1-2$ & $6.9-13.8$ & $\begin{array}{l}\text { Corrugated asbestos shattered; corrugated steel or aluminum panels, fastenings fail, followed by buckling; wood panels } \\
\text { (standard housing) fastenings fail, panels blown in }\end{array}$ \\
\hline 1.3 & 9.0 & Steel frame of clad building slightly distorted \\
\hline 2 & 13.8 & Partial collapse of walls and roofs of houses \\
\hline $2-3$ & $\begin{array}{r}13.8- \\
20.7\end{array}$ & Concrete or cinder block walls, not reinforced, shattered \\
\hline 2.3 & 15.8 & Lower limit of serious structural damage \\
\hline 2.5 & 17.2 & $50 \%$ destruction brickwork of house \\
\hline 3 & 20.7 & $\begin{array}{l}\text { Heavy machines }(3000 \mathrm{lb}) \text { in industrial building suffered little } \\
\text { damage; steel frame building distorted and pulled away from foundations }\end{array}$ \\
\hline $3-4$ & $\begin{array}{r}20.7- \\
27.6\end{array}$ & Frameless, self-framing steel frame building demolished; rupture of oil storage tanks \\
\hline 4 & 27.6 & Cladding of light industrial buildings ruptured \\
\hline 5 & 34.5 & Wooden utility poles snapped; tall hydraulic press $(40,000 \mathrm{lb})$ in building slightly damaged \\
\hline $5-7$ & $\begin{array}{r}34.5- \\
48.2\end{array}$ & Nearly complete: destruction of houses \\
\hline 7 & 48.2 & Loaded train wagons overturned \\
\hline $7-8$ & $\begin{array}{r}48.2- \\
55.1\end{array}$ & Brick panels, $8-12$ inches chick, not reinforced ,fail by shearing or flexure \\
\hline 9 & 62.0 & Loaded train boxcars completely demolished \\
\hline 10 & 68.9 & $\begin{array}{l}\text { Probable total destruction of buildings; heavy machine tools }(7000 \mathrm{lb}) \text { moved and badly damaged; very heavy machine tools } \\
(12,000 \mathrm{lb}) \text { survive }\end{array}$ \\
\hline 300 & 2068 & Limit of crater lip \\
\hline
\end{tabular}




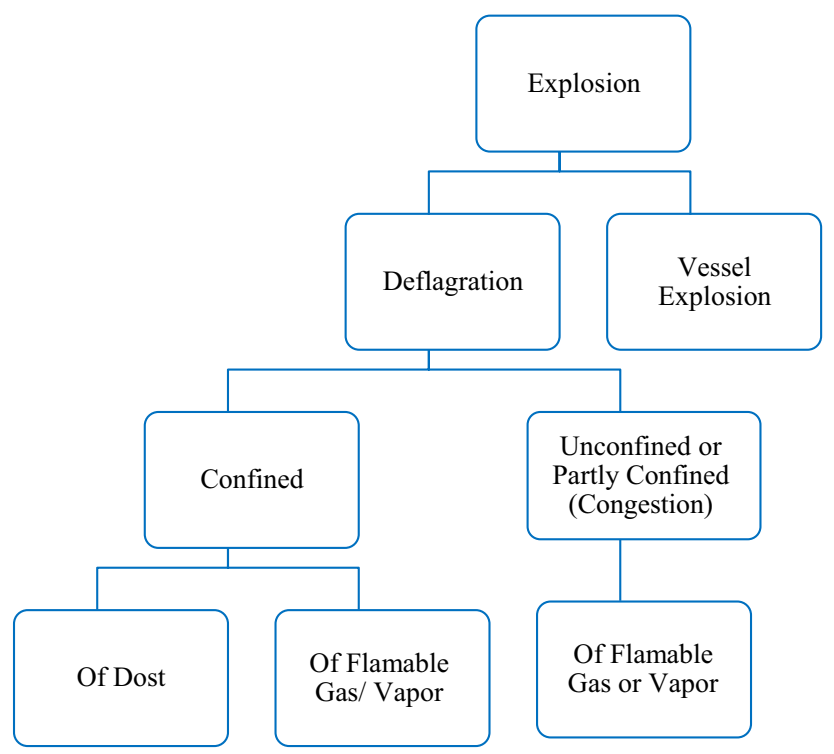

Fig. 1 Type of explosion (Bash and Casal 2007)

scenarios including BELEVE burst, sudden emission, continues emission, flash fire, pool fire, jet fire, ball fire, toxic release, and etc. It is necessary to realize different factors influencing explosion; factors may include replacing the vessel with non-standard and poor-quality one, corrosion in equipment may weaken pressure vessel body's strength and lead to explosion (Bash and Casal 2007; Dziubiński et al. 2006; Wang et al. 2016; Mousavi and Parvini 2016).

Explosion radiation is one of the important results of assessment. Radiations with magnitude of 20 and $37.5 \mathrm{~kW} /$ $\mathrm{m}^{2}$ are very important because the radiation of $20 \mathrm{~kW} / \mathrm{m}^{2}$ cause damage to human, and $37.5 \mathrm{~kW} / \mathrm{m}^{2}$ cause damage to equipment and cause Annie's death. Besides, in safety issue for explosion two pressure is important. These pressure are

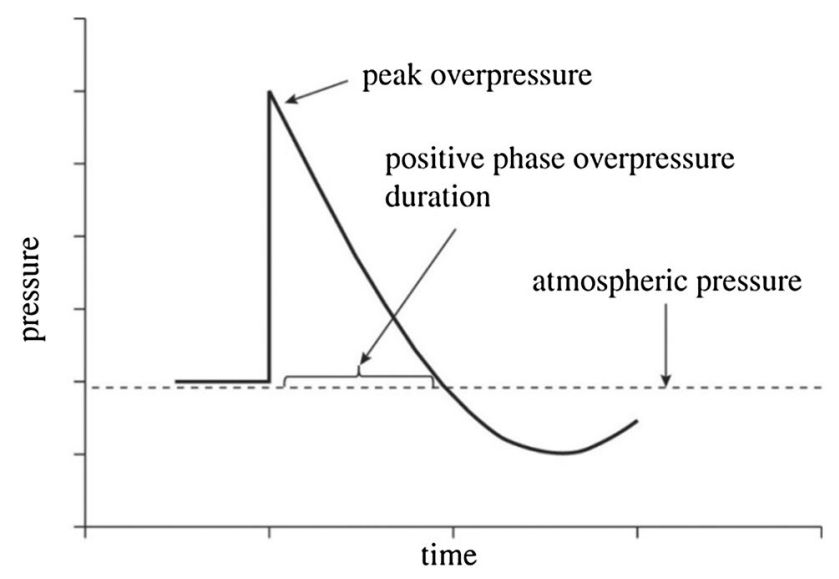

Fig. 2 Blast wave pressure in fixed location (Overpressure levels of concern I response.restoration.noaa.gov.)
Table 4 Original design data derived from nameplate

\begin{tabular}{ll}
\hline Name & ME-03 test separator \\
\hline Type of pressure vessel & Horizontal \\
Serial number & $69-23$ \\
X-ray & $100 \%$ \\
Design pressure & 225 PSIG \\
Design temperature & $122^{\circ} \mathrm{F}$ \\
Shell material & A516-Gr70 \\
Head material & A516-Gr70 \\
Joint efficiency & $100 \%$ \\
Safety factor & 4 \\
Hydrotest pressure & 425 PSIG \\
Volume & $860 \mathrm{ft}^{3}$ \\
Code of design & ASME-SEC VIII-UW12 \\
Data fabrication & 1969 \\
Company number & FG $314,300,710$ \\
\hline
\end{tabular}

0.02 and 0.2 bar. Because 0.02 bar damage limited minor structural damage and damage to human and 0.2 bar cause total destruction (Center for Chemical Process Safety 1999).

Hazard identification of potentially harmful factors in oil, gas and petrochemical industries as well as risk assessment and management aimed to improve safety for the reduction of event power are specifically important. One of these factors is the possibility of explosion in test separatorME03 caused by corrosion (Center for Chemical Process Safety 1999; Markowski 2007).

At the present time, various software packages exist for this purpose but most of them lack high flexibility due to the high volume of calculations, the fact that they are timeconsuming and their inability to perform multi-purpose tasks. To this end, PHAST simulator was used in this study to model the consequences of events. Modeling parameters of this study were the kind and amount of substance, temperature, pressure, and dimensions of pressure vessels walls.

The growing knowledge and emergence of new technologies in the field of industry, production and creation of very complex systems highlights the necessity of implementation of safety principles to prevent accidents and damage to equipment and manpower.

Therefore, these structures can be improved through PHAST software to identify, predict and reduce the risks in order to prevent events in all phases. In addition, the consequences of explosion can be reduced through the presentation of emergency operations plan (Pitblado 2007; Jung et al. 2011).

Use of technological tools for providing safety decision respect to design and operation is the current chemical and 


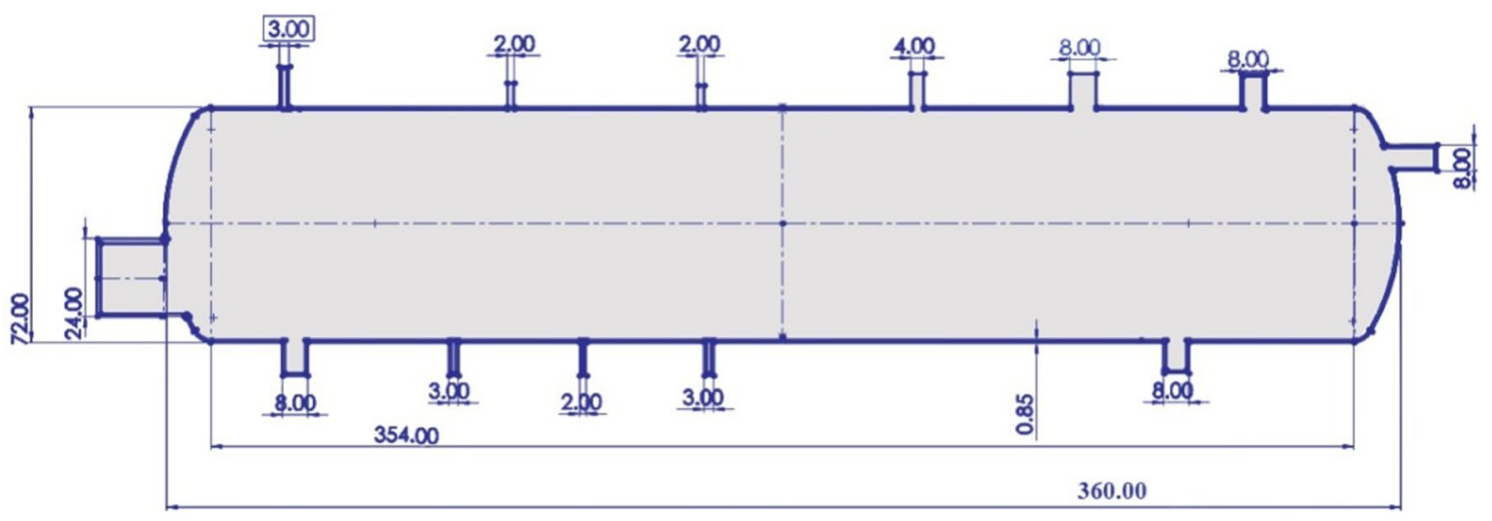

Fig. 3 Schematic of ME-03- side view (in)

Fig. 4 Side view plot of LTAs location in cylindrical shellorigin of axes is 3 o'clock

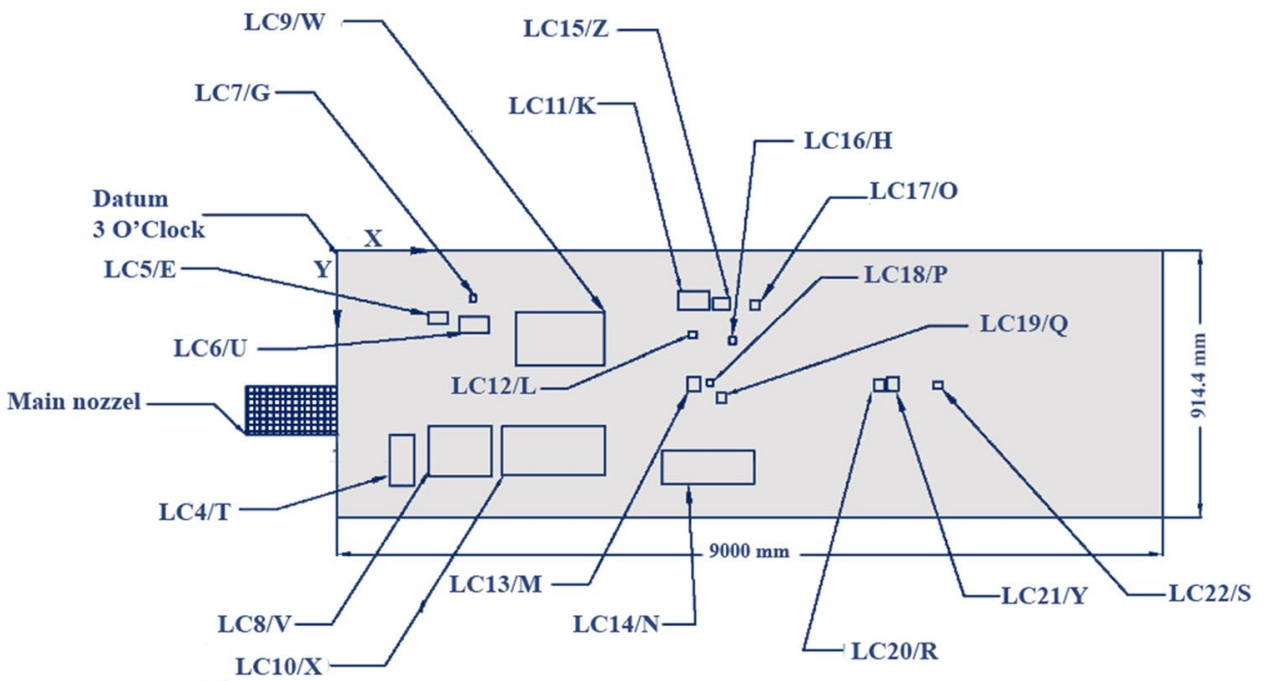

petrochemical plant safety objective. Leak of flammable or toxic material or explosion which is under high pressure can be accounted as acute hazardous incident. Reason of this release may be cracks or corrosion (as pits, local thin areas (LTAs) and uniform corrosion) which threatens the integrity of equipment (Rigas et al. 2003; Sharma et al. 2013).

Hazards in petrochemical plant can divide in two parts: (a) mechanical and (b) chemical hazards. Fire and explosion is one of the major hazards that can be happen due to failure of pressure vessels. The destructive impact of explosion generally covers wider area than the impact region of fire. In this accident, distribution of flammable material in the environment can increase the possibility of secondary accident (Paltrinieri et al. 2015).

These reasons show the importance of prediction of fluid behavior after release and estimate the consequence and damages. These information can cause to providing an extensive safety plan for preventing of initiation of accident. Although result of this analysis can used to form a comprehensive integrity plant that FFS assessment is other part of that.

The purpose of this study is modeling the immediate release (explosion) of ME-03 that operate at high pressure of $225 \mathrm{psi}$ and $100^{\circ} \mathrm{F}$ and capacity of $860 \mathrm{ft}^{3}$ which located at old Nowrooz oil production platform in Bahregan district and investigating its consequences through selected scenarios.

\section{Risk anlysis}

Important part of risk analysis can defined as follow:

a. Define the potential of event sequence and potential incidents

b. Evaluate the consequences 
Table 5 Detail data about shell LTAs

\begin{tabular}{lclcl}
\hline Name & $t_{m m}(m m)$ & $t_{m m}($ in $)$ & $\begin{array}{l}\text { Distance to } \\
\text { nearest LTA } \\
\text { (in) }\end{array}$ & Nearest LTA \\
\hline LC5/E & 8.95 & 0.3523622 & 4.724409449 & (LC6) \\
LC7/G & 13.76 & 0.5417323 & 5.905511811 & (LC6) \\
LC11/K & 12.71 & 0.5003937 & 5.905511811 & (LC15) \\
LC12/L & 14.08 & 0.5543307 & 9.448818898 & (LC1) \\
LC13/M & 13.49 & 0.5311024 & 3.149606299 & (LC18) \\
LC14/N & 12.45 & 0.4901575 & 21.65354331 & (LC10) \\
LC15/Z & 13.87 & 0.546063 & 5.905511811 & (LC11) \\
LC16/H & 11.3 & 0.4448819 & 11.41732283 & (LC15) \\
LC17/O & 13.4 & 0.5275591 & 9.05511811 & (LC15) \\
LC18/P & 13.57 & 0.534252 & 3.149606299 & (LC13) \\
LC19/Q & 14.7 & 0.5787402 & 5.905511811 & (LC18) \\
LC20/R & 13.96 & 0.5496063 & 1.181102362 & (LC21) \\
LC22/S & 14.02 & 0.5519685 & 15.7480315 & (LC21) \\
LC4/T & 12.03 & 0.473622 & 3.149606299 & (LC3) \\
LC6/U & 13.4 & 0.5275591 & 4.724409449 & (LC5) \\
LC8/V & 11.87 & 0.4673228 & 5.905511811 & (LC4) \\
LC9/W & 11.72 & 0.4614173 & 9.05511811 & (LC6) \\
LC10/X & 11.85 & 0.4665354 & 8.267716535 & (LC8) \\
LC21/Y & 13.96 & 0.5496063 & 1.181102362 & (LC8) \\
\hline & & & &
\end{tabular}

c. Estimate impact of incident on peoples, environment and property

d. Estimate the frequency of incident

In fact the estimation of risk can be consider as the combination of risk and frequency of incident for each event and summing of them.

\section{Major accident}

Major accident is defined as "an occurrence such a major emission, fire or explosion resulting from uncontrolled developments in course of operation of any establishment and leading to serious danger to human health and/or environment, and involving one or more dangerous substances" (Fallis and Directive 1997).

Major accidents are associated with one or more of following phenomena:

- Thermal: thermal radiation

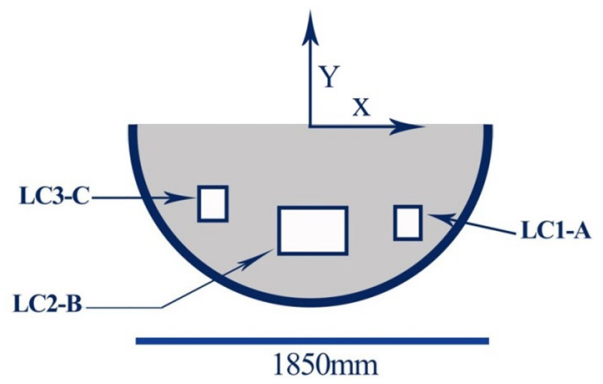

Fig. 5 Location of LTAs on head

Table 7 Weather data of old Nowrooz platform as example-15 August 2015

\begin{tabular}{lllrll}
\hline Time & $\begin{array}{l}\text { Tem- } \\
\text { perature } \\
\left({ }^{\circ} \mathrm{C}\right)\end{array}$ & $\begin{array}{l}\text { Relative } \\
\text { humidity } \\
(\%)\end{array}$ & $\begin{array}{l}\text { Wind } \\
(\mathrm{km} / \mathrm{h})\end{array}$ & Wind gust & $\begin{array}{l}\text { Dew point } \\
\left({ }^{\circ} \mathrm{C}\right)\end{array}$ \\
\hline $0: 30$ & 35 & 33 & 4 & N/A & 11 \\
$5: 30$ & 30 & 29 & 11 & N/A & 9 \\
$6: 30$ & 29 & 28 & 4 & N/A & 9 \\
$8: 30$ & 35 & 33 & 4 & N/A & 10 \\
$9: 30$ & 37 & 39 & 4 & N/A & 18 \\
$11: 30$ & 42 & 40 & 7 & N/A & 8 \\
$12: 30$ & 45 & 42 & 7 & N/A & 6 \\
$14: 30$ & 49 & 48 & 7 & N/A & 13 \\
$15: 30$ & 49 & 42 & 4 & N/A & -12 \\
$17: 30$ & 48 & 41 & 22 & N/A & -13 \\
$18: 30$ & 47 & 40 & 30 & N/A & -14 \\
$20: 30$ & 41 & 36 & 7 & N/A & -17 \\
$21: 30$ & 40 & 35 & 11 & N/A & -15 \\
$23: 30$ & 36 & 32 & 7 & N/A & -7 \\
\hline
\end{tabular}

- Mechanical: blast (pressure wave) and ejection of fragment

- Chemical: release of toxic materials

These accidents can affect people, property and the environment. Human consequences can be physical (fatalities or injuries) or psychological and can affect both the employees of the establishment in which the accident occurs and the external population. The consequences on property are usually the destruction of equipment or buildings. Environmental consequences can be immediate or
Table 6 Detail results of LTA inspection data

\begin{tabular}{lllcl}
\hline Name & $\mathrm{X}(\mathrm{in})$ & $\mathrm{Y}(\mathrm{in})$ & $\mathrm{S}(\mathrm{in})$ & $\mathrm{C}(\mathrm{in})$ \\
\hline LC1/A & 18.8976378 & -29.13385827 & 3.937007874 & 3.149606299 \\
LC2/B & 6.692913386 & -27.55905512 & 14.96062992 & 9.448818898 \\
LC3/C & -23.62204724 & -26.77165354 & 13.38582677 & 6.299212598 \\
\hline
\end{tabular}


Table 8 Average value of essential weather variable in summer of 2015 of old Nowrooz platform

\begin{tabular}{llll}
\hline $\begin{array}{l}\text { Average tem- } \\
\text { perature }\end{array}$ & $\begin{array}{l}\text { Average wind } \\
\text { speed }\end{array}$ & $\begin{array}{l}\text { Average dew } \\
\text { point }\end{array}$ & $\begin{array}{l}\text { Average relative } \\
\text { humidity }\end{array}$ \\
\hline $39.62{ }^{\circ} \mathrm{C}$ & $13 \mathrm{~km} / \mathrm{h}$ & $4{ }^{\circ} \mathrm{C}$ & $57 \%$ \\
\hline
\end{tabular}

delayed and include the release of a hazardous material into the atmosphere, into the soil or into water. In addition, major accidents usually cause indirect losses such as loss of profits by the company involved (Bash and Casal 2007).

Major accidents are associated with the occurrence of fires, explosions or atmospheric dispersions of hazardous materials. An accident can also involve more than one of these phenomena: a fire can follow an explosion, a fire can cause the explosion of a vessel, and an explosion can cause the dispersion of a toxic cloud.

Although Table 1 shows that explosion has second rank of major accident but potential of economic loss of these accident may be more than other. Table 2 discuss about different accept of these accident.

\section{Consequence modeling}

Consequence modeling involves the determination of the impacts of process accidents involving hazardous materials on people, the environment and the process. The amount and form of hazardous material released is determined for toxic materials, flammables, and explosives (called the source term). The dispersion of the released material through and beyond the facility is studied. The distance traveled and area covered is determined. For toxic materials, their effects on people and the environment evaluated. For flammables, the impact of the heat radiation from a fire on people and equipment is calculated. For explosive materials, the impact of blast overpressures on people, equipment and structures are calculated.

Types of explosions modeled include confined, unconfined, and dust explosions as well as BLEVEs (boiling liquid expanding vapor explosion), thermal decompositions, and runaway reactions. ${ }^{1}$

First step in consequence analysis is chose of accident scenario which can make hazardous consequences. As the primary step of consequence modeling, scenario selection

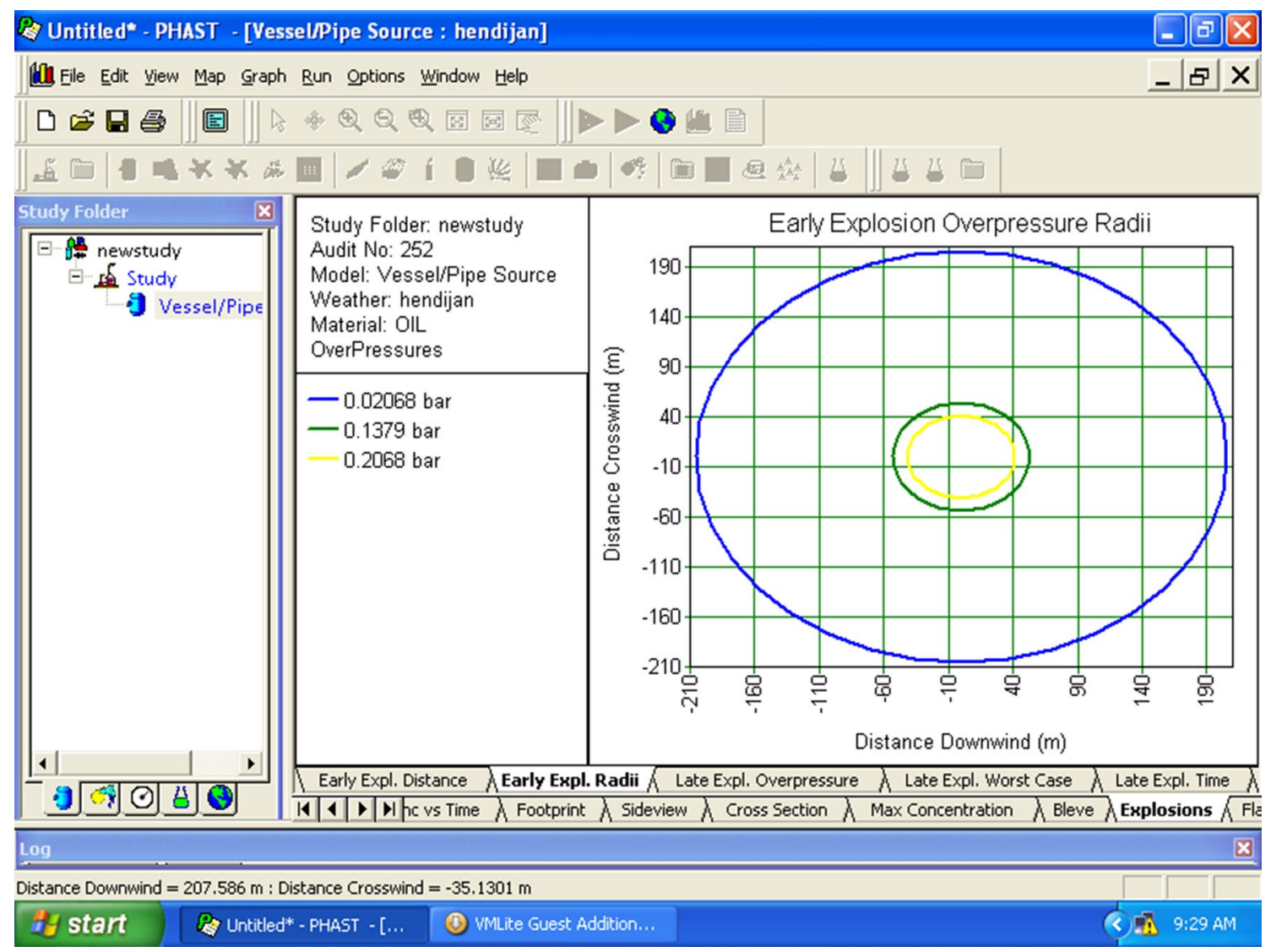

Fig. 6 Overpressure due to ME-03 explosion

$\overline{1}$ Consequence Modeling. 


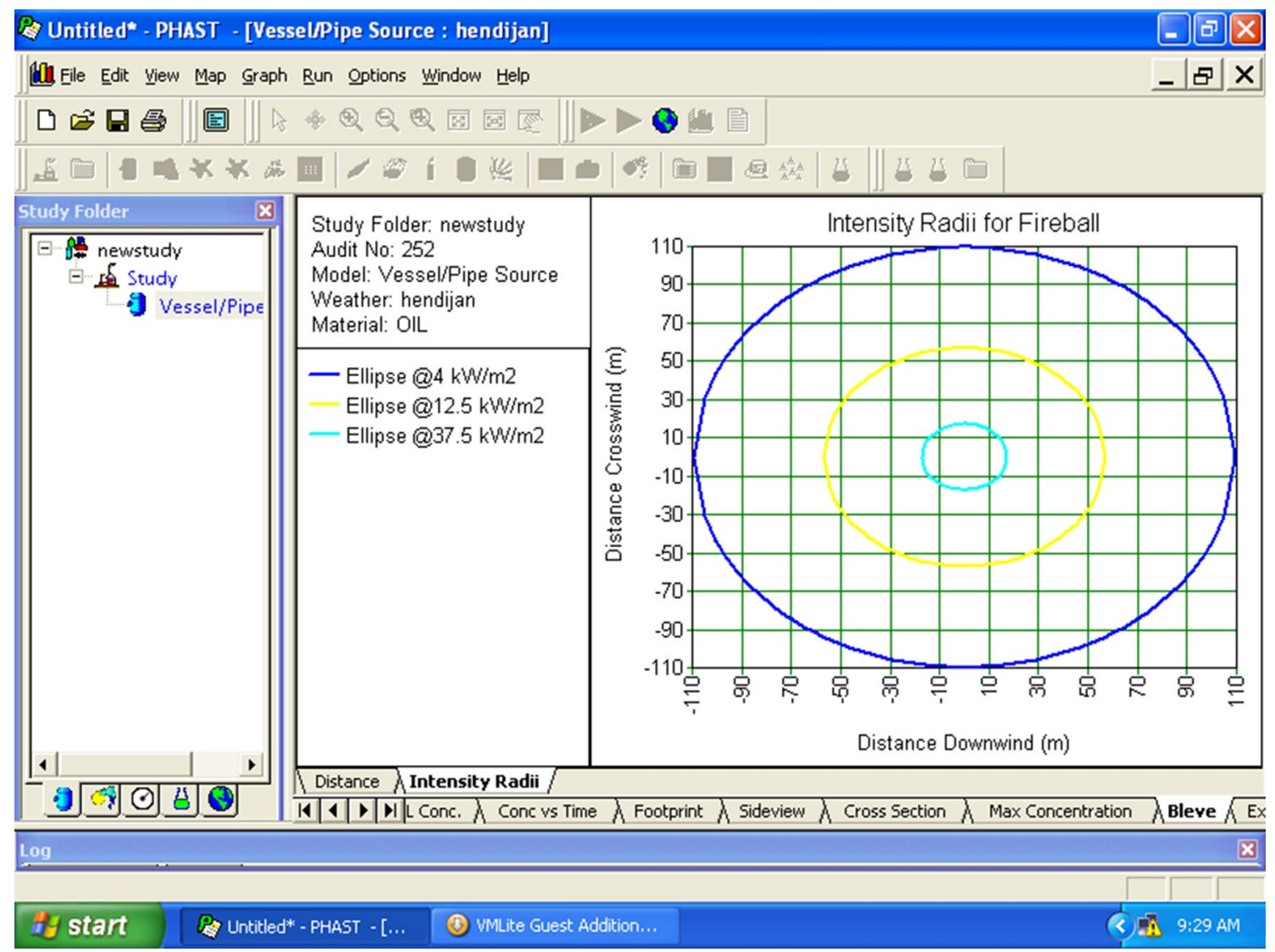

Fig. 7 BELEVE result due to failure of ME-03

plays an important role in reliability of result. The next step of modeling is scenario modeling (Yousefzadegan et al. 2011).

In thisinvestigation utilized the PHAST software based on DNV standard for complete steps modeling. Table 3 shows a brief review of common consequence analysis software.

\section{Explosion modeling}

Explosions are associated with major accidents involving mechanical phenomena. Explosions occur when there is a rapid increase in volume due to the expansion of a pressurized gas or vapor, the sudden vaporization of a liquid (physical explosions), or a fast chemical reaction (often combustion). Figure 1 shows category of explosions.

Type of explosion can define as follow:

\section{Vapor cloud explosions}

Chemical explosions involving a significant amount of a flammable gas or vapor mixed with air. They are usually associated with the release of flammable liquids or vapor-liquid mixtures. A vapor cloud explosion is always accompanied by a flash fire and the severity of the mechanical effects (blast) is determined by the mass involved and the characteristics of the environment (confinement/congestion) (Ronza et al. 2011).

\section{Vessel explosions and BLEVEs}

Physical explosions caused by the sudden failure of a vessel containing a pressurized gas or superheated liquid (i.e., a liquid at a temperature that is significantly higher than its boiling point at atmospheric pressure) in equilibrium with its vapor. Under certain conditions (currently under discussion) this type of explosion may be referred to as a BLEVE (boiling liquid expanding vapor explosion) (Ronza et al. 2011).

The major accidents can occur in industrial installations or during the transportation of hazardous materials are usually related to a loss of containment. The loss of containment can be caused by an impact, by the failure of a piece of equipment (a pipe or tank) due to the effects of corrosion, by human error during a loading or unloading operation, or by various other factors. The loss of containment 


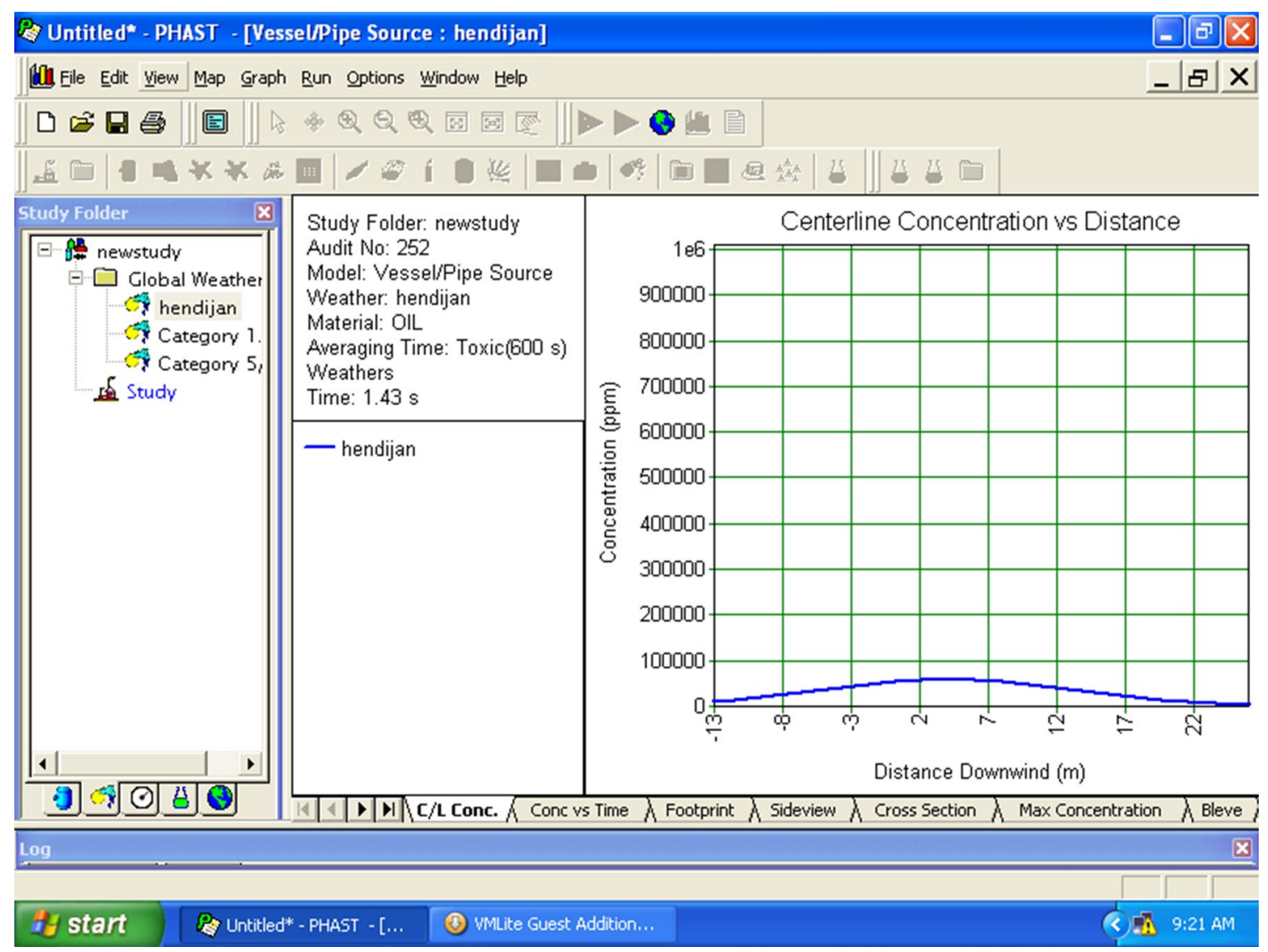

Fig. 8 Concentration versus distance

can also be a consequence of the accident itself, for example in the case of the explosion of a pressurized tank (Bash and Casal 2007).

\section{Impact of explosion}

\section{Overpressure/ Blast Wave/ Shockwaves}

Overpressure, also called a blast wave, refers to the sudden onset of a pressure wave after an explosion. This pressure wave is caused by the energy released in the initial explosion, the bigger the initial explosion, the more damaging the pressure wave. Pressure waves are nearly instantaneous, traveling at the speed of sound.

Overpressure phase is followed by a region that have negative pressure or under pressure. Therefore, it is obvious that the most important part of results in explosion consequence modeling is study of peak pressure. Figure 2 shows a diagram of pressure change in fix location.

Although a pressure wave may sound less dangerous than a fire or a toxic cloud, it can be just as damaging and just as deadly. The pressure wave radiates outward and generates hazardous fragments (such as building debris and shattered glass). Additionally, these waves can damage buildings or even knock them flat often injuring or killing the people inside them. The sudden change in pressure can also affect pressure-sensitive organs like the ears and lungs. ${ }^{2}$

\section{Effect of blast pressure on body and structuers}

Table 3 shows the consequence of damage due to overpressure in structures:

Because of using with Table 3 and Fig. 2 in results (finding over pressure and introducing it, and knowing about damage of each overprresure and predict explosion) these must be mention in introduction.

\section{Results and discussion}

Figure 3 shows a schematic of ME-03. Fabrication data of pressure vessel are listed in Table 4.

\footnotetext{
${ }^{2}$ Overpressure levels of concern response.restoration.noaa.gov.
} 


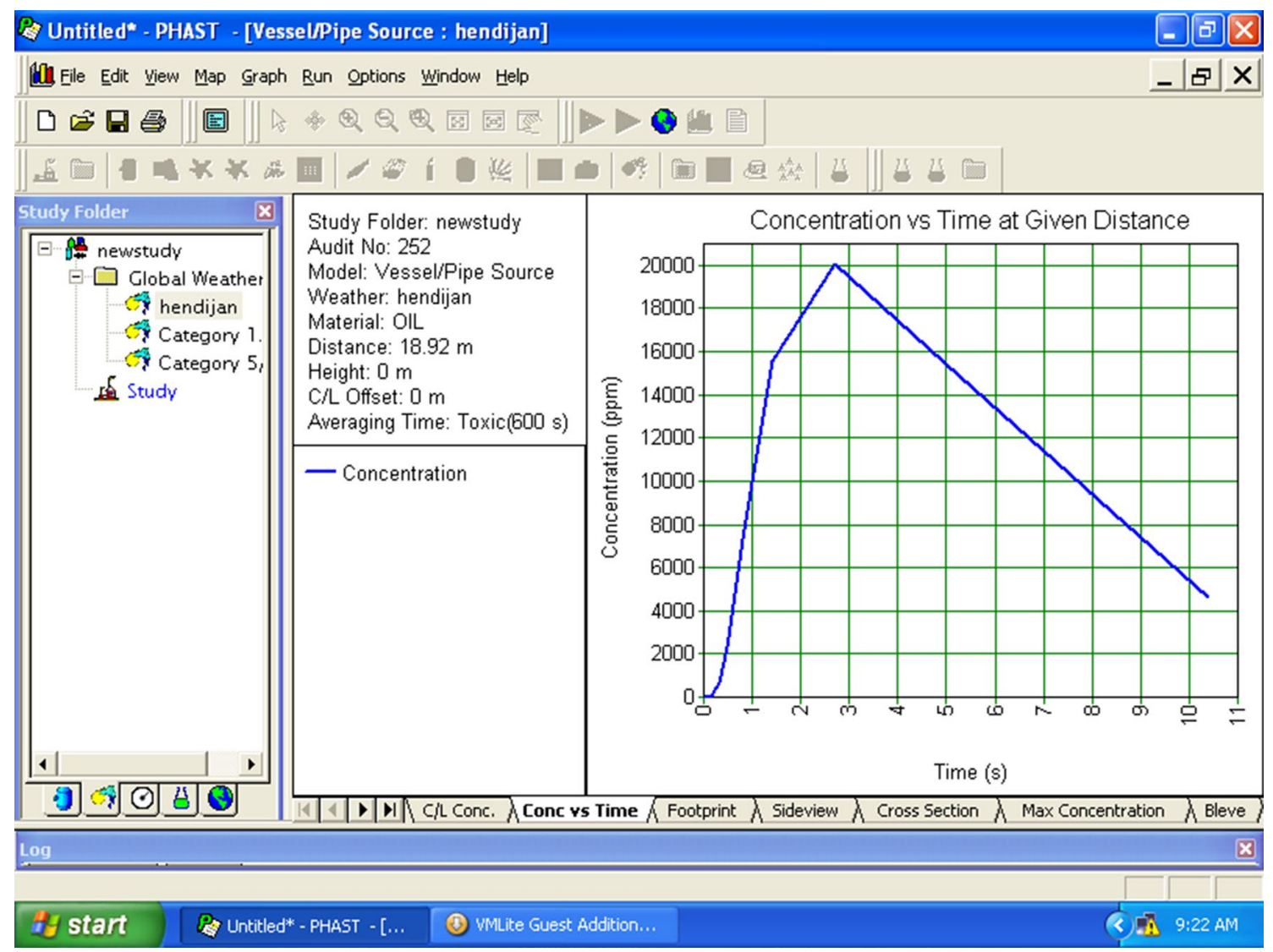

Fig. 9 Concentration of released fluid versus time

Detailed PAUT inspection shows widely scattered local thin areas in different location of cylindrical body.

Figure 4 showed the side view of pressure vessel. Rectangles show the location of corrosion in separator and origin is located in the center of cylindrical body. Detailed results of LTAs summarized in Tables 5 and 6. Figure 5 is schematic of damaged area on elliptical are.

\section{Climate}

Bahregan has hot and humid weather. The temperature of this port in the hottest month of the year is about $49^{\circ} \mathrm{C}$ (August) and in the coldest month of the year is about $8^{\circ} \mathrm{C}$ (December). The maximum humidity in Bahregan is $67 \%$ in December and its minimum humidity is about $46 \%$ in May. More than 1000 climate data of Bahregan is analyzed, Table 7 shows an example of used data for a day.

Average result of 480 records in summer of 2015 listed in Table 8:

Figure 6 shows the distance and value of overpressure due to explosion of ME-03. Result shows in a circle in 25 radius the overpressure is 0.2068 bar. Consequence of this overpressure as mentioned in Table 3 can expressed as "Heavy machines in industrial buildings suffer little damage; steel frame building distorted and pulled away from foundation". This value is exceeding to overpressure threshold caused serious damage to equipment, building and humans.

These results clearly show important of safe servicing of studied pressure vessel. High pressure, high humidity atmosphere, presence of water as an important corrosion factor, severity of service condition and importance of continuing to servicing make ME-03 critical equipment in Old-Nowrooz platform.

In safety issue for explosion two pressures is important. These pressure are 0.02 and 0.2 bar. Because 0.02 bar damage limited minor structural damage and damage to human and 0.2 bar cause total destruction. Therefore, the radius for these overpressure to be calculated. Results of assessment for overpressure of 0.02 bar radius are $200 \mathrm{~m}$ and for 0.2 bar radius is $30 \mathrm{~m}$. So probable failure of ME- 03 undoubtly has mortal consequence and caused huge economic lost and this subject clearly shows importance of safe future servicing. 


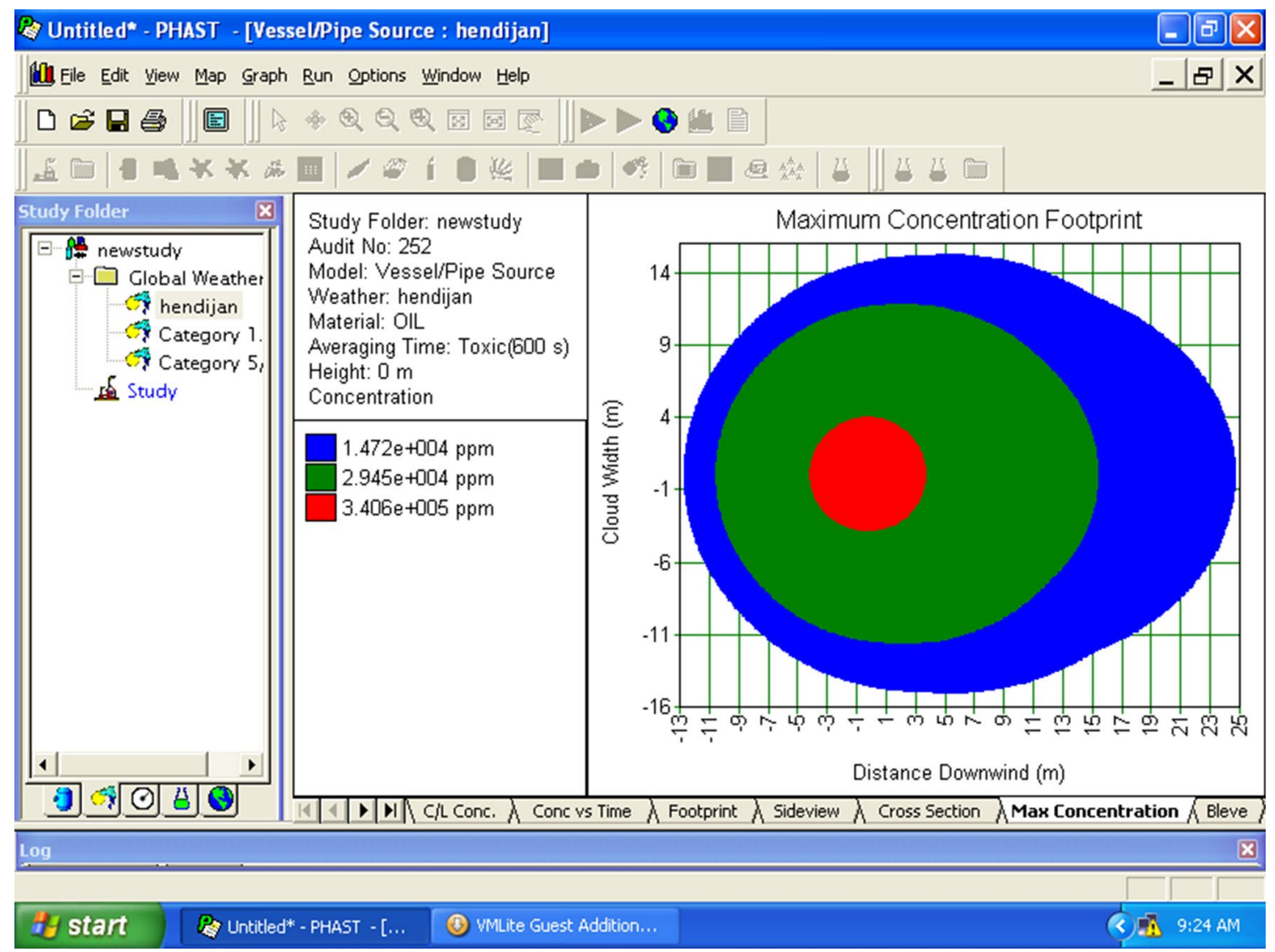

Fig. 10 Maximum concentration verus distance from top view

Figure 7 shows the radiation results of explosion. In safety issues, radiations of 20.0 and $37.5 \mathrm{~kW} / \mathrm{m}^{2}$ is very important because the radiation of $20.0 \mathrm{~kW} / \mathrm{m}^{2}$ cause damage to human, and $37.5 \mathrm{~kW} / \mathrm{m}^{2}$ cause damage to equipment and cause Annie's death, from the PHAST result, the radius of $37.5 \mathrm{~kW} / \mathrm{m}^{2}$ is about $21 \mathrm{~m}$.

Figure 8 depict concentration of released content vs. distance. Maximum concentration in the location of explosion accrues and is more than $5000 \mathrm{ppm}$. Figure 9 shows concentration of released fluid versus times. Concentration of released content reaches to the maximum after $3 \mathrm{~s}$ after explosion to 20,000 ppm. Figures 10 and 11 show top view and side view of this distribution.

\section{Conclusions}

Safe working of this separator will cause to prevent from huge cost of untimely shutdown, cost of loss of production, cost of operation condition over derating and cost of releasing content due to probable failure. In addition, this Increment will provide a good time for engineering analysis to perform complete cost assessment for future remediation technique such as replacing or derating of operation condition.

A consequence assessment with PHAST software performed for reaching to an engineering sense of failure consequence. In safety issues radiations of 20.0 and $37.5 \mathrm{~kW} / \mathrm{m}^{2}$ is very important because the radiation of $20.0 \mathrm{~kW} / \mathrm{m}^{2}$ cause damage to human, and $37.5 \mathrm{~kW} / \mathrm{m}^{2}$ cause damage to equipment and cause Annie's death, from the PHAST result the radius of $37.5 \mathrm{~kW} / \mathrm{m}^{2}$ is about $21 \mathrm{~m}$. Also in safety issue for explosion two pressure is important. These pressures are 0.02 and 0.2 bar. Because 0.02 bar damage limited minor structural damage and damage to human and 0.2 bar cause total destruction. Therefore, we must calculate the radius for these over pressure. Result of assessment for over pressure, $0.02 \mathrm{bar}$ radius is $200 \mathrm{~m}$ and for 0.2 bar radius is $30 \mathrm{~m}$. Concentration of released fluid reach to $20,000 \mathrm{ppm}$ in three second after explosion and decrease gradually. So probable failure of ME-03 undoubtedly has mortal consequence and caused huge economic lost and this subject clearly shows importance of safe future servicing. 


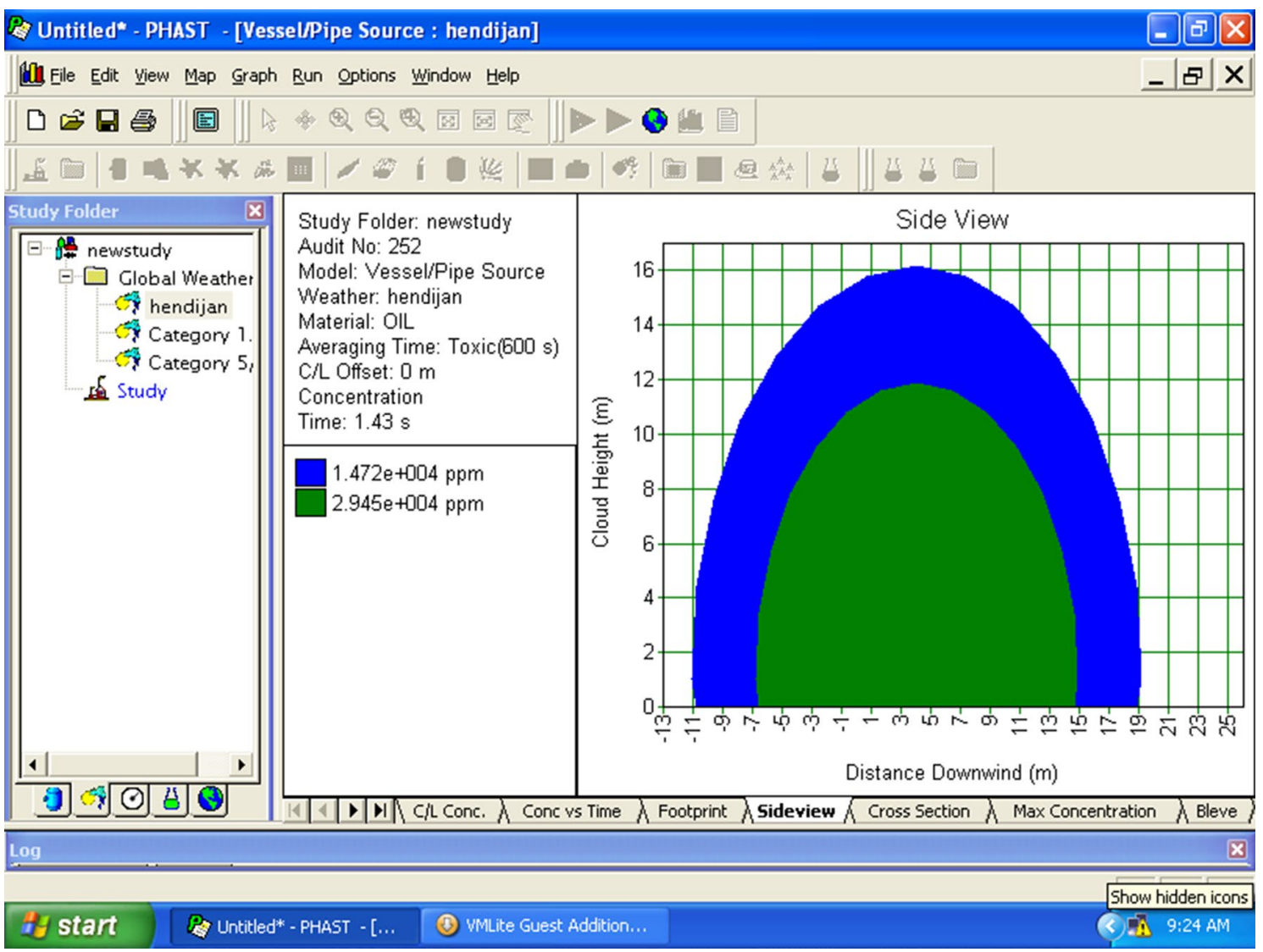

Fig. 11 Distance and concentration distribution of released fluid due to failure from side view

Open Access This article is distributed under the terms of the Creative Commons Attribution 4.0 International License (http:// creativecommons.org/licenses/by/4.0/), which permits unrestricted use, distribution, and reproduction in any medium, provided you give appropriate credit to the original author(s) and the source, provide a link to the Creative Commons license, and indicate if changes were made.

\section{References}

Bash E, Casal J (2007) Evaluation of the effects and consequences of major accidents in industrial plants, vol. 8. Elsevier, Amsterdam

Brito J, de Almeida AT (2009) Multi-attribute risk assessment for risk ranking of natural gas pipelines. Reliab Eng Syst Saf 94(2):187-198

Center for Chemical Process Safety Process (1999) Guidelines for chemical process quantitative risk analysis, 2nd edn. Wiley, Hoboken

Dadashzadeh M, Khan F, Hawboldt K, Amyotte P (2013) An integrated approach for fire and explosion consequence modelling. Fire Saf J 61:324-337

Dziubiński M, Fratczak M, Markowski AS (2006) Aspects of risk analysis associated with major failures of fuel pipelines. J Loss Prev Process Ind 19(5):399-408
Fallis A, Directive C (1997) Council directive 96/82/EC of 9 December 1996 on the control of major accident hazards involving dangerous substances. Off J Eur Communities 53(9):1689-1699

Jung S, Ng D, Diaz-Ovalle C, Vazquez-Roman R, Mannan MS (2011) New approach to optimizing the facility siting and layout for fire and explosion scenarios. Ind Eng Chem Res 50(7):3928-3937

Markowski AS (2007) exLOPA for explosion risks assessment. J Hazard Mater 142(3):669-676

McIntyre DR, Ford E, Weber M (2009) Recent developments in the analysis of fires, explosions, and production disruption incidents in chemical plants and oil refineries. Process Saf Prog 28(3):250-258

Mousavi J, Parvini M (2016) Analyzing effective factors on leakageinduced hydrogen fires. J Loss Prev Process Ind 40:29-42

Nabhani N, Esfandyari M (2015) Analyzing the consequences of mixture release in the South Pars Gas Field Development in Iran. Int J Mech Prod Eng 115(4):20-23

Paltrinieri N, Tugnoli A, Cozzani V (2015) Hazard identification for innovative LNG regasification technologies. Reliab Eng Syst Saf $137: 18-28$

Pandya N, Gabas N, Marsden E (2012) Sensitivity analysis of phast's atmospheric dispersion model for three toxic materials (nitric oxide, ammonia, chlorine). J Loss Prev Process Ind 25(1):20-32

Pitblado R (2007) Potential for BLEVE associated with marine LNG vessel fires. J Hazard Mater 140(3):527-534

Rigas F, Konstandinidou M, Centola P, Reggio GT (2003) Safety analysis and risk assessment in a new pesticide production line. $\mathbf{J}$ Loss Prev Process Ind 16(2):103-109 
Ronza A, i Fàbrega JC, Sánchez JAV (2011) Contributions to the risk assessment of major accidents in port areas, no. November. Universitat Politècnica de Catalunya, Barcelona

Sharma RK, Gurjar BR, Wate SR, Ghuge SP, Agrawal R (2013) Assessment of an accidental vapour cloud explosion: lessons from the Indian Oil Corporation Ltd. accident at Jaipur, India. J Loss Prev Process Ind 26(1):82-90

Soman R, Sundararaj G (2015) Accidental release of chlorine from a storage facility and an on-site emergency mock drill: a case study. Sci World J. doi:10.1155/2015/48321
Wang K, Liu ZZ, Qian X, Li M, Huang P (2016) Comparative study on blast wave propagation of natural gas vapor cloud explosions in open space based on a full-scale experiment and PHAST. Energy Fuels 30(7):6143-6152

Yousefzadegan MS, Masoudi AM, Ashtiani YK, Kambarani M, Pishbin SI (2011) Consequence analysis for probable accidents of filter separators installed in gas pressure reduction stations. Gas 3333(3):20 